\title{
Novas regulações escolares: quais os impactos sobre as preocupações dos professores?
}

\author{
New school regulations: \\ what are the impacts on the teacher's concerns?
}

Marie-Claude Riopel ${ }^{2}$

\section{Resumo}

Desde o início dos anos 1990, os ministérios educacionais distritais têm implementado por todo o Canadá um número de novas políticas e reformas. Levará algum tempo para que estas mudanças tenham um impacto visível em escolas e salas de aula, mas, nos últimos cinco anos ou mais, esses efeitos têm se tornado aparentes e estão ainda em desenvolvimento. Os professores se encontram na situação complexa da necessidade de manter um mínimo de comprometimento para atuar com dedicação profissional e, ao mesmo tempo, com a necessidade de serem flexíveis e adaptáveis por causa das condições do trabalho em desenvolvimento e do contexto político. O Estudo de Pessoal Escolar iniciou uma investigação sobre as preocupações diárias dos professores em relação aos seus trabalhos. Este artigo relata as preocupações que foram reveladas através da análise de 240 entrevistas conduzidas com professores em escolas de ensino médio e fundamental em três distritos canadenses.

Palavras-chave: Regulações; Políticas Escolares; Professores

\section{Abstract}

Since the early 1990's the provincial ministries of education across Canada have implemented a number of new policies and reforms. It took some time for these changes to have a visible impact on schools and classrooms, but in the last five years or so, those effects have become apparent and are still evolving. Teachers find themselves in the complex situation of needing to maintain a sense of commitment in order to perform with professional dedication, while at the same time needing to be flexible and adaptable in the face of evolving working conditions and policy contexts. The School Personnel Study set out to investigate the impact of the introduction of these changes on the day-to-day concerns of teachers regarding their works. This paper reports on those concerns as revealed by an analysis of 240 interviews conducted with teachers in elementary and secondary schools in three Canadian provinces.

Keywords: Regulations; School Policies; Teachers

1 Agradeço a contribuição da senhora Mylène Des Ruisseaux, profissional de pesquisa no CRIFPE, na análise dos dados contidos neste trabalho, e igualmente à senhora Martine Cloutier, que nos facilitou o acesso à documentação ligada ao conceito de preocupação.

2 Ph. D., Pesquisadora, Universidade de Montreal, CRIFPE - Centro de Pesquisa Interuniversitário sobre a Formação e a Profissão Docente (Canadá). marie.claude.riopel@umontreal.ca. 


\section{INTRODUÇÃO}

Os diferentes sistemas canadenses de educação criaram novas políticas educativas e reformas importantes a partir do início dos anos 1990 (GRIMMET at al., 2006). Com efeito, nós assistimos, nas diferentes províncias, à emergência de discursos oficiais e criação de políticas, visando à redução das despesas em educação, ao crescimento do poder dos pais na escola, à imputabilidade dos funcionários da escola, à descentralização dos poderes de decisão, à livre competição entre as escolas privadas e as escolas públicas (LESSARD, 2006; BEN JAAFAR; ANDERSON, 2004). Essas mudanças são relativamente recentes e, numa larga medida, ainda estão ocorrendo hoje. Elas têm início em momentos diferentes e com ritmos diferentes em cada província. Assim, o que nos interessa é saber como os funcionários das escolas se adaptam a essas mudanças e como percebem esses impactos sobre seu trabalho (RIOPEL; TARDIF, 2005). Nesse contexto de mobilidade, os professores são chamados a reagir e a se adaptar à nova paisagem educativa, mas ao mesmo tempo são convidados a manter o seu engajamento na profissão sobre novas bases, para continuar a sua missão de educação (RIOPEL, 2005). Quais são as repercussões da introdução dessas mudanças sobre o engajamento no trabalho e sobre o trabalho cotidiano dos professores? O que é que as preocupações cotidianas dos professores têm a ver com o contexto de mudanças impostas pelas reformas educativas e pelas novas políticas escolares implantadas durante os últimos anos?

Para responder a essas perguntas, utilizaremos dados colhidos em entrevistas individuais feitas junto a 240 professores de escolas primárias e secundárias, estabelecidas nas três maiores províncias do Canadá (Quebec, Ontário, Colúmbia Britânica). Veremos que os professores têm preocupações múltiplas, e, sob certos aspectos, similares, mesmo vivendo em províncias diferentes. Assim, as preocupações mencionadas pelos professores se apresentam ao mesmo tempo como reação às políticas específicas de suas províncias e como reflexo de um papel que eles devem desempenhar junto aos alunos e na sociedade. Em outros termos, pouco importando onde vivem, muitos professores se mostram inquietos diante das quatro realidades seguintes: 1) os problemas sociais que afetam seus alunos; 2) o êxito escolar de todos os alunos; 3) certas condições de trabalho; 
e 4) a permanência de sua filosofia da educação num contexto de mudanças social e política.

Este texto está organizado em cinco partes. Apresentaremos, na primeira parte, as bases essenciais do contexto, para situar a introdução de novas políticas escolares no Canadá. Traremos em seguida algumas explicações sobre o conceito de preocupação. As considerações metodológicas do estudo serão apresentadas na terceira parte, que será seguida de uma apresentação dos resultados, ilustrados pelas entrevistas e por nossas interpretações. E na conclusão, especificaremos os pontos relevantes desta análise.

\section{Reformas escolares e políticas educativas: tendências PANCANADENSES E INICIATIVAS LOCAIS}

Desde o início dos anos 1990, os sistemas canadenses de educação passaram por importantes mudanças. Trata-se realmente de sistemas de educação, já que no Canadá temos 13 Ministérios da Educação distintos, repartidos em 10 províncias e em 3 territórios. Como a educação é de alçada provincial e não federal, é inevitável que haja diferenças entre províncias, pois cada sistema procura responder às características, às aspirações culturais e aos valores das populações locais. Essas diferenças mostram também especificidades ligadas à história dos sistemas escolares e às suas transformações ao longo do tempo. No entanto, apesar das diferenças entre as províncias, observa-se a emergência de políticas educativas variadas que, mesmo se criadas em diferentes momentos durante os anos 1990, perseguem objetivos semelhantes. Por exemplo, os governos de províncias, engajados em lutas contra o déficit, efetuaram cortes no orçamento, muitas vezes drásticos, que levaram a uma redução importante dos recursos destinados às escolas. Os currículos escolares foram revisados de diferentes maneiras e em diferentes momentos da década, mas sempre de modo a favorecer a aquisição das competências necessárias na nova sociedade do saber. Ao mesmo tempo, novas modalidades de avaliação, freqüentemente padronizadas e concebidas para melhor comparar os resultados dos alunos, acompanharam os novos currículos e foram implantadas nas escolas. Para citar um outro exemplo, os governos também introduziram novas formas de divisão dos poderes de decisão entre os diferentes escalões de instâncias locais (escolas), intermediárias (comissões e distritos escolares) e provinciais (ministérios), 
assim como entre os dirigentes de estabelecimentos escolares, os professores e os pais, com o objetivo de diminuir a burocracia escolar. $\mathrm{Na}$ prática, a descentralização do poder de decisão é proposta como uma via de acesso para maior eficácia dos sistemas escolares e maior autonomia dos atores escolares. Essa autonomia não é mais uma resposta "contra a organização" (LESSARD, 2006), mas uma nova prescrição da organização. A emergência dessas legislações concede claramente mais poder aos pais de alunos, identificados como parceiros na gestão das escolas. E, simultaneamente, concede também mais poder de decisão aos dirigentes das escolas, que exercem esse poder dentro de estruturas mais descentralizadas. Esse movimento de descentralização, inscrito numa lógica de imputabilidade reconhecida, implica aumento das responsabilidades e das obrigações dos atores. Mais autonomia e mais controle, descentralização e aumento do poder das escolas levam, de um lado, ao reconhecimento do papel fundamental dos professores e dos diretores de escola na educação dos alunos e, de outro lado, estimulam a profissionalização do ensino. Mas, ao mesmo tempo, esse movimento aumenta o peso da responsabilidade dos atores, no que se refere ao êxito dos alunos, e visa a melhor controlá-los. Dito de outra maneira, os atores são chamados, efetivamente, a exercer maior autonomia nos seus estabelecimentos, mas eles devem realizar seu trabalho levando em conta as novas e numerosas exigências, que são ao mesmo tempo de ordens orçamentária e política, mas também profissional. Com efeito, o engajamento, a autonomia e a responsabilidade profissional, nesse contexto, aparecem como qualidades "prescritas e obrigatórias" (LESSARD, 2006). Essas lógicas de regulação são também uma resposta às pressões internacionais de uniformização dos sistemas, e se inscrevem dentro das tendências nacionais e internacionais (CALDWELL, 1999; TARDIF; LESSARD, 1999; OCDE, 1998). Assim, podemos dizer que há, no Canadá, um duplo movimento de influência: as realidades locais, que outrora eram mais independentes umas das outras e fortemente inscritas num contexto, influenciam doravante o contexto nacional; e o contexto nacional é influenciado ao mesmo tempo por essas realidades locais e pelas realidades internacionais. A questão que se apresenta para nós é a de saber se e como esses movimentos e essas mudanças estruturais são percebidos e sentidos pelos professores.

Esse contexto de mudança é acompanhado de um fenômeno de renovação do pessoal da escola. Devemos dizer, antes de mais nada, que esse pessoal, composto por professores, diretores de escolas, profissionais 
não docentes (p. ex., psicopedagogos, fonoaudiólogos etc.) constitui $6 \%$ da mão-de-obra ativa do país. Em 2001, 300.000 professores regulares trabalham com 5,5 milhões de alunos em mais de 16.000 escolas primárias e secundárias. Desde o início dos anos 2000, observa-se uma tendência importante de renovação dos professores e de outros membros do quadro escolar, pois um terço desses funcionários, aproximadamente, se aposentarão ao longo da década que se inicia (GERVAIS; THORNY, 2001). Em muitas das escolas primárias e secundárias do Canadá, as condições de trabalho dos professores se transformam. Vários aspectos dessas condições são determinados pelas autoridades provinciais em cada uma das províncias, quer seja o Ministério da Educação, quer seja o governo. É o caso, por exemplo, do número permitido de alunos numa classe ou do número de horas de trabalho do professor. Em contrapartida, as regras de acesso aos recursos materiais e humanos, ou as modalidades de contratação e de promoção, são da alçada das autoridades locais. Mas em todas as províncias, observa-se uma diversificação das tarefas e dos papéis dos professores, estreitamente ligada às necessidades do público escolar. Por exemplo, nas grandes cidades, as classes são cada vez mais de natureza multiétnica, e os alunos devem ser escolarizados em uma segunda ou uma terceira língua, já que eles não possuem nem o francês nem o inglês como língua materna.

Outros alunos provêm de meios socioeconômicos desfavorecidos. Em 1989, a Câmara dos Comuns do Governo Federal adotou uma resolução unânime, onde se comprometia a "eliminar a pobreza infantil no Canadá até o ano 2000". Em 2001, a pobreza das crianças aumentou em 21\%. De cada 6 crianças, uma vive hoje na pobreza, ou seja, 1.139.000 crianças (RIOPEL; TARDIF, 2003). ${ }^{3}$ Outros alunos têm necessidades particulares, por causa de dificuldades de aprendizado ou de comportamento. Esses alunos são, cada vez mais, integrados às classes regulares do sistema escolar público. Isso conduz a um aumento das necessidades de orientação e acompanhamento desses alunos. Mas, como vimos, o sistema escolar funciona dentro de uma lógica de racionalização

3 Ser pobre, no Canadá, significa, na opinião da maioria, não dispor de recursos suficientes para manter o nível médio de vida da maior parte da população. Essa definição diz respeito a certas condições básicas de vida como uma boa alimentação e uma habitação segura. O Conselho Nacional do Bem-Estar Social indicava, num relatório publicado no verão de 2006, referente a 2002 e 2003, que 4,9 milhões de habitantes viviam na pobreza no Canadá. 
dos recursos e muitas vezes só oferece um acesso limitado às medidas de ajuda para os alunos e de apoio aos professores que acolhem esses alunos em suas classes. Os professores são, dessa maneira, confrontados com expectativas sociais elevadas, de tal modo que suas missões de educação, de socialização, de instrução e de qualificação se sobrepõem e, às vezes, se entrechocam. Por isso, não é surpreendente que os professores se interroguem sobre suas práticas de ensino e sobre a avaliação dos aprendizados, especialmente por causa da diversificação crescente do público escolar e dos novos desafios pedagógicos que esta acarreta, e também pela orientação dos novos currículos e pelas políticas de imputabilidade ligadas aos resultados dos alunos. Em última análise, as condições de trabalho dos professores se tornaram muito mais complexas, e acarretaram uma multiplicação de seus papéis profissionais, além de colocá-los diante de expectativas sociais por vezes contraditórias (HARGREAVES, 1997; TARDIF; LESSARD, 1999). É bem verdade que mudanças estruturais de tamanha amplitude deveriam, em princípio, afetar a vida dos professores. Mas como é que elas se traduzem para eles? De que modo elas os influenciam? Nesse contexto, nos interrogamos sobre as formas que tomam essas mudanças na realidade cotidiana e na vida profissional dos professores.

\section{AS PREOCUPAÇõES dOS PROFESSORES}

A fim de situar o conceito de preocupação, recorreremos inicialmente às definições de uso comum, tais como se encontram em alguns dicionários. As definições encontradas no Robert (2006) e no Multi Dictionnaire (2003) falam de "um desassossego, uma inquietação que ocupa o espírito; uma idéia fixa, uma obsessão". Trata-se igualmente de "um pensamento, um sentimento, uma consideração que ocupa o espírito de maneira dominante, e até mesmo exclusiva." (Trésor de la langue française). O Littré (1872) designa uma preocupação como um estado. "Estado de uma pessoa cujo espírito está inteiramente ocupado com uma opinião preconcebida, favorável ou desfavorável”. Em suma, uma preocupação evoca, ao mesmo tempo, sentimentos e inquietações face a uma eventualidade cujo resultado é incerto. Os trabalhos de G. E. Hall, A. A. George e S. M. Rutherfort, realizados no âmbito de suas reflexões sobre o processo de mudança no meio da educação, contribuíram de um modo significativo ao estudo do conceito de preocupação. Eles definem esse conceito como "uma mistura de sentimentos, de inquietação, de questionamentos, de reflexões face a uma eventualidade cujo resultado pode ser favorável ou ameaçador”. Em 
resumo, tal como mostrado na síntese de Cloutier (2006), uma preocupação é "uma atividade mental" que ocupa ou retém o espírito; estar preocupado significa "estar em estado de alerta mental" em relação a um objeto. A intensidade desse estado de alerta varia muito de uma pessoa para a outra, de acordo com as situações, segundo as características pessoais dos indivíduos e de acordo com a sua relação com o objeto de preocupação. Assim, os indivíduos identificam as situações que suscitam as preocupações com os seus próprios traços de caráter, com suas experiências e com seus conhecimentos. A intensidade de uma preocupação pode portanto variar da inquietação à idéia fixa, indo até a obsessão. Essa dimensão subjetiva é importante, já que a questão não é reconhecer ou validar a legitimidade da preocupação, mas sim situá-la no contexto em que ela reveste sentido para o indivíduo. Quanto à fonte das preocupações, ela é, em geral, de duas ordens: ela pode estar ligada a objetivos que a pessoa impõe a si mesma (preocupação de fonte interna) ou que lhe são impostos de fora (preocupação de fonte externa). Em Quebec, Savoie e Bareil (1999, p. 89) interessaram-se pela noção de preocupação a partir de seus trabalhos sobre a mudança organizacional. Eles a definem como "um assunto sobre o qual nos questionamos e sobre o qual gostaríamos de ter explicações ou elementos de resposta. Não se trata necessariamente de um problema, mas de inquietações e de questões face a uma situação atual ou antecipada". Enfim, Brassard (2003) concebe a preocupação como "uma questão que tem importância para o indivíduo, que lhe diz respeito estreitamente, que está ligada a seus interesses e para a qual ele procura dar uma resposta com a ajuda de informações fornecidas por um ou mais atores de sua organização". Essa definição nos parece muito interessante, já que ela engloba as precedentes, e ainda acrescenta as dimensões profissional e institucional. Com efeito, o indivíduo preocupado tentará suscitar o interesse de seus colegas, de seu patrão, em suma, dos atores de sua organização para dar sentido às suas preocupações. Por isso, foi essa definição que escolhemos para examinar e melhor entender o sentido das palavras dos professores, quando eles relataram aquilo que os preocupava no contexto de seu trabalho, no momento de nosso encontro.

\section{O contexto do estudo e o seu método}

Antes de mais nada, queremos situar esta análise das preocupações de professores canadenses no contexto mais vasto de sua realização. A reflexão apresentada aqui se inscreve dentro de um programa de pesquisa 
mais amplo sobre o pessoal das escolas canadenses primárias e secundárias. Essencialmente, nosso objetivo principal é analisar, numa perspectiva pancanadense, comparativa e longitudinal, as principais mudanças que marcam a situação e a evolução dos professores e dos diretores de escola, entre o fim dos anos 1990 e a primeira metade da década de 2000 (TARDIF et al., 1999). ${ }^{4}$ Em seu conjunto, esse programa de pesquisa se interessa pelas condições de trabalho e pela renovação do pessoal do ensino, pelo impacto das reformas e das políticas escolares sobre os professores e diretores de estabelecimentos escolares, pela profissionalização do ensino e da formação para o ensino e pelas transformações das práticas de ensino e das práticas de gestão em administração escolar. Uma grande parte desse programa de pesquisa propõe seguir o caminho profissional de 500 professores e diretores de escola, estabelecidos em diferentes regiões urbanas do Canadá. Estendendo-se por um período de cinco anos, esse estudo longitudinal, e principalmente qualitativo, permite entender melhor as dinâmicas de adaptação face às mudanças vividas no mundo escolar. Diferentes temas foram abordados durante esses cinco anos do estudo, graças a questionários ${ }^{5}$ e a entrevistas. ${ }^{6}$ Os relatos dos professores que fazem o objeto da presente análise foram colhidos na ocasião da primeira entrevista.

$4 \quad$ No âmbito do programa de pesquisa Grands travaux de recherche concertée, o Conselho de Pesquisas em Ciências Humanas do Canadá (CRSH) outorgou uma subvenção de 2,5 milhões de dólares para a equipe de pesquisa dirigida por Maurice Tardif, a fim de conduzir, entre os anos 2000 e 2006, um estudo nacional sobre a evolução do pessoal de ensinos primário e secundário no Canadá.

5 Os questionários são aplicados anualmente a todos os participantes $(\mathrm{n}=500)$. 0 primeiro questionário permitiu colher informações a respeito do perfil profissional dos participantes e das relações que eles mantêm com seus colegas e com os pais de alunos. Além disso, identificamos suas percepções no que diz respeito aos impactos das políticas e das reformas escolares sobre seu trabalho. O objetivo do segundo questionário era aprofundar o tema das relações profissionais e das práticas pedagógicas. O terceiro visava a conhecer melhor suas percepções dos saberes profissionais que estão na base de seu trabalho. 0 quarto questionário permitiu abordar principalmente os temas da diversidade dos alunos e dos saberes profissionais dos novos professores. O último questionário, enfim, tratava essencialmente da satisfação no trabalho e das características dos alunos.

6 A primeira entrevista foi realizada em 2003, junto a professores e a diretores de escolas das cidades de Montreal, Toronto e Vancouver $(n=300)$. Essa entrevista visava à narração de um episódio de carreira. A segunda entrevista foi realizada em 2005, junto a essa mesma população. Ela se concentrou sobre três temas: a diversidade cultural na escola, a interação das tecnologias da informação e da comunicação e o impacto das políticas. 


\section{A entrevista}

$\mathrm{Na}$ primavera de 2003, foram realizadas 240 entrevistas individuais, junto aos professores que participavam do estudo. A entrevista era semidirigida e visava a melhor conhecer o desenvolvimento de suas carreiras; ela durava em média 70 minutos. O relato, guiado por nossas perguntas, estruturou-se em volta de temas que marcam a carreira do professor: os motivos da escolha dessa carreira, o desenvolvimento de sua formação inicial, o desenvolvimento de sua inserção profissional, a evolução de sua carreira, entre essa inserção e a situação presente, indicando o que mudou nesse período (mudança de escola, de nível, de alunos etc.). Em seguida, os participantes detalharam as características de sua situação atual (seu público, a relação com seus colegas e a direção da escola etc.) e, finalmente, eles descreveram seus projetos para o futuro, a curto e médio prazos. Durante a conversa sobre a situação presente, pedimos aos participantes para expressar o que os preocupava mais, naquele momento, em relação ao seu trabalho.

As respostas a essa pergunta formam o conjunto principal de dados para o presente estudo. Trata-se verdadeiramente de dados provocados (VAN DER MAREN, 1996), isso quer dizer que eles foram obtidos ou criados pela própria pesquisa. Para proceder à análise, efetuamos em primeiro lugar uma leitura dos dados de primeiro nível (PAILLÉ, 1994), em que se falava das preocupações dos professores. Em seguida, nós procedemos a uma categorização aberta dos elementos presentes, isto é, não utilizamos categorias definidas anteriormente. Essa codificação dos elementos presentes permitiu determinar, em cada entrevista, uma ou várias preocupações para cada participante. As preocupações foram então agrupadas segundo suas similitudes, de maneira a efetuar uma síntese do conjunto das preocupações mencionadas e a refletir sobre os laços que se tecem entre elas e os contextos político e escolar.

\section{O QUESTIONÁRIO}

Os participantes também preencheram um questionário, contendo 23 perguntas referentes a diferentes temas: a experiência profissional, os estudos, as relações profissionais, a satisfação no trabalho, os fatores que influenciam a escola e a percepção das mudanças em curso, em educação e na sociedade. Esse instrumento permitiu igualmente obter informações sociodemográficas (p. ex., gênero, idade, estado civil, número de filhos, 
lugar de nascimento, língua materna, língua de uso). Para os fins dessa análise sobre as preocupações dos professores, só conservamos essas últimas informações com a finalidade de melhor descrever as características desse grupo de professores.

\section{OS PARTICIPANTES DO ESTUDO}

São professores do primário $(55,8 \% ; n=240)$, do secundário $(41,3 \%$; $\mathrm{n}=240)$ e de escolas que ministram os dois tipos de ensino $(2,9 \% ; \mathrm{n}=$ 240). Essas pessoas trabalham em Montreal (na província de Quebec), em Toronto (na província de Ontário) e em Vancouver (na província da Colúmbia Britânica) e participam voluntariamente do estudo.

Tabela 1

Número de professores que preencheram o questionário e participaram da entrevista, por cidade

\begin{tabular}{c|c|c}
\hline & Questionário 1 & Entrevista 1 \\
\hline Montreal & 64 & 63 \\
\hline Toronto & 86 & 88 \\
\hline Vancouver & 90 & 89 \\
\hline Total & 240 & 240 \\
\hline
\end{tabular}

No momento de preencher o questionário, em 2003, os participantes tinham em média 39 anos. Vários jovens professores aceitaram participar do estudo. Com efeito, 39\% têm entre 24 e 35 anos, $n=240$. A maioria dos participantes são mulheres $(68,5 \% ; n=240)$. A maior parte dos participantes são casados ou vivem com um companheiro $(65,5 \%$; $\mathrm{n}=$ 240). Um pouco mais da metade $(52,7 \% ; n=240)$ não têm filhos.

As línguas maternas dos participantes são principalmente o inglês $(47,9 \% ; \mathrm{n}=236)$ e o francês $(34,7 \% ; \mathrm{n}=236)$. Em $15,3 \%$ dos casos, a língua materna é uma língua não reconhecida como língua oficial no Canadá. Aproximadamente $2 \%$ dos participantes disseram ter duas línguas maternas: o inglês e o francês, o francês e uma outra língua ou ainda o inglês e outra língua.

Cerca da metade da amostra é composta de professores tendo menos de 9 anos de experiência $(46,4 \% ; n=237)$. Aqueles que têm entre 9 e 16 
anos de profissão constituem $32,2 \%$ da amostra, enquanto que aqueles que têm mais de 17 anos de experiência representam 21,4\%. O Gráfico 1 ilustra o número de participantes que começaram a trabalhar a partir de 1966. 47\% $(\mathrm{n}=230)$ dos participantes começaram a lecionar após 1993.7

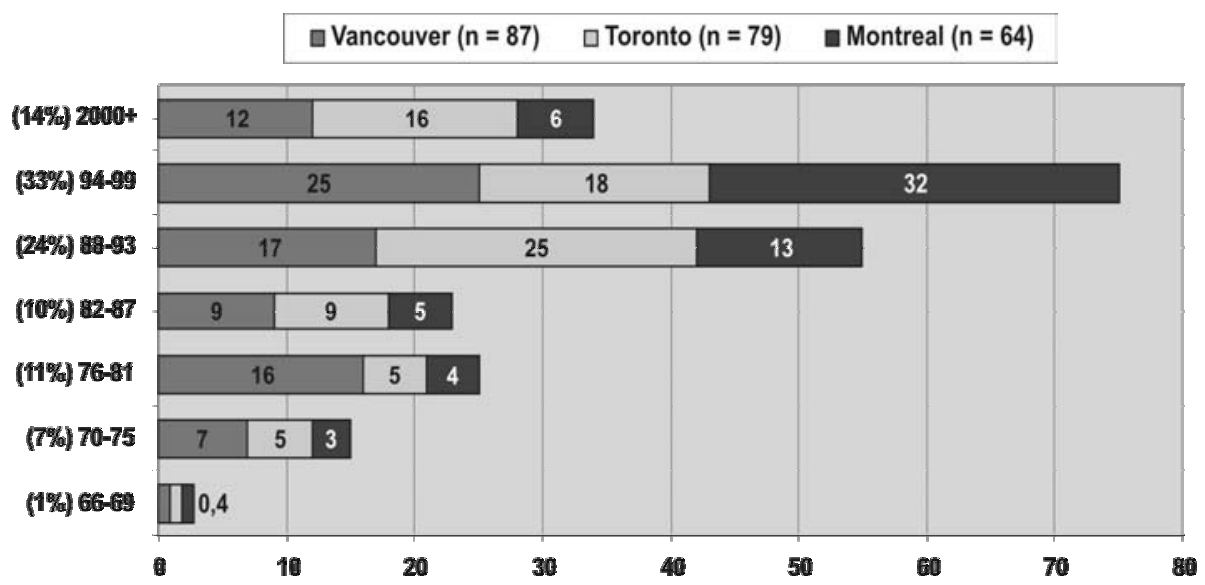

GRÁFICO 1 - Número de participantes conforme a data de início na profissão

Essa amostra de conveniência (MILES; HUBERMAN, 2003) não nos permite generalizar os resultados ao conjunto do corpo docente no Canadá, mas oferece a ocasião de examinar aquilo que é vivido pelos professores nas três maiores cidades deste país. Na descrição dos resultados a seguir, faremos um retrato qualitativo das preocupações dos professores.

\section{Contextos diferentes, PReocupações comuns}

Durante a análise, descobrimos que as preocupações dos professores podiam ser agrupadas em três grupos distintos. O primeiro reúne as preocupações que se inscrevem na experiência específica dos indivíduos, no momento da entrevista. Uma professora nos disse, por exemplo: "Atualmente, estou preocupada com a organização de uma viagem com meus alunos.” Essa preocupação corresponde a uma inquietação restrita

Essa característica profissional está diretamente ligada à maneira como os participantes do estudo longitudinal foram escolhidos. Apesar de essas estratégias terem variado ligeiramente de uma cidade a outra, foi especificado que desejávamos fazer participar tanto professores experientes quanto recém-formados, e que a participação deles deveria durar 5 anos. 
e individual. Ela se apresenta como uma dificuldade a curto prazo e só raramente está ligada a reformas ou a mudanças de grande envergadura do ponto de vista do próprio professor. O segundo grupo de preocupações reúne as que aparecem "em cacho" em cada província e que, naturalmente, estão estreitamente ligadas às mudanças próprias a esse território (p. ex., percepção de uma injustiça nas condições de trabalho, Ontário; nova política da adaptação escolar, Quebec; transformação do Colégio dos professores, Colúmbia Britânica). ${ }^{8}$ Essas inquietações refletem o estado de espírito dos membros de uma comunidade profissional e são atualmente objeto de uma análise provincial (GRIMMET; WALDERN, 2006). O terceiro tipo reúne as preocupações comuns aos professores, sem relação com a sua província de origem. Para realizar nossa análise, voltamos a nossa atenção para as particularidades dessas preocupações comuns. $\mathrm{O}$ que é que preocupa professores separados por milhares de quilômetros, exercendo sua profissão em contextos e condições tão diferentes? Quatro tipos de preocupações aparecem assim, independentemente do local de trabalho dos professores, isto é, elas são comuns aos professores do Quebec, de Ontário e da Colúmbia Britânica. Essas preocupações dizem respeito a: 1) problemas sociais que afetam os alunos; 2) êxito escolar de todos os alunos; 3) certas condições de trabalho dos professores e 4) a permanência de sua filosofia da educação num contexto de mobilidades social e política.

\section{O ENFRAQUECIMENTO dO TECIDO SOCIAL NA VIDA DOS ALUNOS}

O primeiro grupo de preocupações diz respeito à presença de problemáticas relativas ao enfraquecimento do tecido social na vida dos alunos, ao absenteísmo dos alunos, a situações de violência e de pobreza. Os professores estão inquietos em relação a essas dimensões da vida dos alunos.

[...] Há crianças que chegam às 7 h30, há crianças que deixam a escola às 18h. São portanto dias excessivamente longos para crianças de 5 anos. Então, as crianças sentem um grande cansaço, muitas frustrações, e a gente sente que há uma fadiga de estar sempre em

8 O Colégio dos Professores (tradução livre da autora para The British Columbia College of Teachers) é um órgão estatutário, de auto-regulamentação da profissão de professor. Criado em 1987, sob a lei de Teaching Profession Act, visa estabelecer modelos para a educação, a competência e a conduta profissional dos funcionários escolares da província. 
grupo ... Há crianças que têm muita dificuldade de viver neste ritmo... Isto corresponde certamente à metade (dos alunos da minha classe)... A qualidade das relações que eles têm na família é como que utilitária; a gente vê que estas famílias estão estafadas, mas eu não considero que os pais sejam responsáveis por esta situação, é a realidade dos pais que trabalham. E há também toda a questão, para certas crianças, da guarda compartilhada, dos divórcios, da instabilidade, às vezes da pobreza... Isto afeta muito. É por isto que eu acrescento ao meu ensino períodos de relaxamento, coisa que eu não fazia antes (5077-469). ${ }^{?}$

Essas preocupações não parecem estar ligadas diretamente a uma política escolar provincial ou a qualquer reforma na educação. Elas são de outra natureza, de outro nível. O que se expressa aqui é uma preocupação quanto ao bem-estar dos alunos, uma inquietação face às transformações sociais e culturais que afetam todos os cidadãos, crianças e pais: o aumento da pobreza, a transformação das famílias, o enfraquecimento do tecido social. Numerosos professores se sentem tocados pelo que vivem os alunos fora da escola e pensam que devem tentar, de uma forma ou de outra, levar isso em conta em seu ensino.

\section{O ÊXITO ESCOLAR DE TODOS OS ALUNOS}

O segundo grupo de preocupações está ligado à motivação em aprender e ao êxito escolar de todos os alunos.

A disciplina (e) a perseverança, para mim, é importante; eu acho que, uma vez que uma disciplina foi instaurada, o resto vai bem. Eu quero tornar meus alunos perseverantes, eu quero que eles realizem tarefas. O que mais me aflige é quando eu sei que há um aluno que não conseguiu terminar (o que ele devia fazer). Às vezes, eu deveria dizer para mim mesmo que isto não tem importância, que o aluno está numa situação difícil, mas eu quero que todos os alunos tenham êxito. Para mim, é importante (5058-932).

Eu tenho alunos que estão terminando o ensino secundário. Eles são muito inteligentes e muito motivados em aprender. Como posso fazer com que continuem motivados? Como posso prepará-los aos estudos superiores? Esta é certamente uma responsabilidade a

9 Esses números referem-se às entrevistas. 
mais para mim, este ano. É muito estimulante, mas ao mesmo tempo, muito angustiante. Eu me pergunto se os estou preparando realmente bem. Eu penso sempre nisto; é uma responsabilidade maior para mim, agora (4157-560).

Aqui se entra no coração da função do ensino: transmitir valores, motivar e fazer os alunos, todos os alunos, aprenderem. Diante dos desafios colocados pela escolarização dos alunos e pela massificação da educação, os professores expressam uma preocupação que parece decorrer da visão que eles têm de seu papel e de sua função social. Fazer tudo o que for possível para levar os alunos ao êxito escolar é uma evidência para esses professores. Pode-se pensar que eles interpretam a obrigação de resultados como uma obrigação de meio (PERRENOUD, 2004) e que esse sentimento de obrigação é, com efeito, uma resposta pragmática à questão do êxito escolar.

\section{As CONDIÇÕES DE TRABALHO}

O terceiro grupo de preocupações, relatadas por numerosos participantes de todas as cidades, diz respeito às condições de trabalho, particularmente à proporção professor/alunos, à carga de trabalho e ao difícil acesso aos recursos. Ainda que esses aspectos das condições de trabalho se apresentem de modo diverso em cada província, vários professores manifestam sua insatisfação e mostram-se preocupados quanto ao impacto que elas podem ter sobre os alunos ou sobre eles próprios.

O número de alunos em classe. Eu estou limitado, agora, porque eu não posso dispensar um ensino individualizado. Numa classe (nível secundário) eu tenho de 30 a 35 alunos. Eu não tenho tempo de ajudar a todos (4132-491).

Um jornalista escreveu que não havia ligação direta entre a proporção mestre/alunos e a melhora dos resultados escolares. Não concordo... A chave do sucesso dos meus alunos é que eu os conheça. Como posso fazer isto se eu não tenho alguns minutos para cada um deles todo dia? Como chegar a conhecê-los e permitir que tenham êxito? Muitas pessoas pensam que nossa profissão consiste tão somente em transmitir informações aos alunos e em fazer que estes as assimilem. Nossa profissão não é isto (1039-602). 
O aumento do número de alunos por classe tem por conseqüência inevitável um aumento da carga de trabalho.

Deveria haver menos alunos por sala. Fala-se disto em relação aos primeiros níveis do primário. Mas eu creio que todas as classes deveriam ter menos alunos. Atualmente, eu me sinto sobrecarregado pela avaliação e pela correção dos trabalhos de meus 31 alunos. Levando em conta também o número elevado de matérias que eu ensino, eu nem sempre consigo levar todos os cadernos para casa, de noite. Há tanta coisa para se fazer. Eu não tenho mais vida pessoal (4141-491).

Minha carga de trabalho só aumenta. Vou citar apenas o número de alunos: eu tenho sete grupos e 217 alunos por semana. É uma carga de trabalho incrível. Isto se torna difícil sobretudo pelo tipo de relação que eu quero ter com os alunos. Quanto mais eu envelheço, mais se torna difícil saber o nome deles. Eu acabei por desistir, é impossível, se eu quiser sobreviver. Mesmo se eu tenho experiência, eu sinto que estou andando para trás, como nos primeiros anos de minha carreira: eu tento sobreviver (1096-497).

Assim, as preocupações se afirmam face à acumulação e ao amálgama das problemáticas ligadas à proporção mestre/alunos, ao aumento da carga de trabalho que daí decorre e às políticas de redução dos recursos que prevalecem nas comissões escolares.

São os cortes no orçamento que afetam diretamente os alunos. Nós temos menos recursos a oferecer-lhes, menos tempo para lhes apresentar atividades significativas; e isto só está aumentando. É a pior situação que eu vi até agora. O aumento do número de alunos por classe, mais uma conseqüência dos cortes. Isto afeta severamente a qualidade do ensino. E nas classes, agora, todos os alunos são integrados, mesmo aqueles que não são capazes de estar lá, isto faz com que a dinâmica nas classes deteriore. Isto é difícil e afeta diretamente o ensino (1021-898).

O que me preocupa verdadeiramente é que eu não consigo separar estas coisas, elas estão ligadas entre si. Eu mencionei a importância de promover a instrução pública, mas a falta de recursos é importante, há alunos demais nas classes, pouco apoio para os alunos que têm necessidades particulares; tudo isto tem impactos reais (1020-536). 
Vários professores das três cidades oferecem, através de suas preocupações, uma visão clara e global da situação. Eles parecem perceber com acuidade as conseqüências das mudanças sobre suas condições de trabalho.

\section{Manter sua filosofia da educação}

Finalmente, numerosos foram os professores que se mostraram preocupados com relação à manutenção de sua filosofia da educação nesse contexto de pressão e de mobilidade. Essa manutenção parece ser uma resposta às novas exigências e às novas obrigações: se, por exemplo, eles não têm outra opção que a de aceitar que haverá, com efeito, mais alunos em suas classes e que eles deverão, doravante, trabalhar com menos recursos. A questão que se apresenta então é a seguinte: Quando tudo é urgente, quando tudo se transforma, qual é a minha prioridade? Quais são os aspectos que eu domino? Não se trata apenas de reagir às novas exigências ou de contestar a validade das mudanças. Trata-se, antes, de formular sua própria resposta, de modo que ela seja também uma via de acesso para continuar a atualização de seus valores educativos e para manter uma forma de engajamento profissional.

O que me preocupa é como melhor responder às necessidades dos alunos, é isto que me aflige. Eles têm necessidades variadas. É uma reflexão que envolve vários fatores; por exemplo, no plano da organização escolar: como poderíamos imaginar uma organização escolar diferente para permitir aos professores trabalhar mais em equipe? Para que os alunos possam criar laços com a comunidade, as empresas, fazer estágios no exterior? Para organizar projetos variados? (5032-714).

Eu sinto que estamos numa situação onde a única coisa importante é a avaliação. Para mim, isto é apenas uma parte do aprendizado. Há outras, por exemplo desenvolver sua reflexão crítica. Isto significa que eu preciso, como professor, ter uma visão de para onde vão os alunos, no futuro. Eu não creio que o governo se preocupe com isso, mas eu me preocupo (1026-511).

Ser professor é um pouco como uma espécie de vocação... É preciso acreditar nela... Em certos momentos, eu queria apenas ganhar o mínimo e ter o espírito em paz e talvez viver mais tempo; é realmente uma ocupação muito difícil. É preciso verdadeiramente dar o melhor e ir mais longe, porque senão, não somos felizes (1001-551). 
Ao ler esses trechos, temos o sentimento de que é difícil para um professor exercer hoje sua profissão se ele não dispuser de uma visão do papel a desempenhar junto aos alunos e na sociedade. Conduzidos por aquilo que desejam realizar em classe, junto a seus alunos ou em suas escolas, muitos professores têm a possibilidade de interpretar as mudanças a partir de sua visão da educação, das prioridades que eles defendem, daquilo que continua sendo fundamental para eles. É assim que, na nossa opinião, os professores tentam reunir aquilo que eles querem levar em conta, dada sua identidade profissional; e aquilo que eles devem levar em conta, tendo em vista sua missão. Enfrentar as mudanças implica então, para eles, harmonizar preocupações de fonte interna, ligadas a objetivos que eles próprios se atribuíram, e preocupações de fonte externa, impostas do exterior.

\section{As PReocupações e as políticas: que vínculos estabelecer?}

Pode-se pensar, como Savoie-Zajc (2006), que os professores no Canadá vivem uma "intensificação do trabalho" (VAN DEN BERG, 2002 apud SAVOIE-ZAJC, 2006), proveniente de um aumento das pressões governamentais, por intermédio das políticas e das reformas escolares. Os trabalhos de Hargreaves (2003) vão na mesma direção: o autor considera que o aumento da pressão pode levar os atores ao esgotamento e a perder o sentido do trabalho por causa da rapidez das mudanças e da falta de tempo para integrá-las. Os professores que nós encontramos também consideram que seu trabalho se intensificou efetivamente. Para retomar a idéia de Cloutier (2006), "seu estado de alerta" os leva a se perguntar se o novo contexto transforma, com efeito, o sentido que eles dão ao trabalho. Ainda que certos participantes tenham dito estar cansados, ou, às vezes, esgotados, poucos dentre eles afirmaram que o seu trabalho não tinha sentido para eles.

Por definição, o ensino é uma profissão na qual reinam exigências, e, geralmente, os professores evoluem nesse contexto tentando integrálas, frustrá-las, contorná-las ou liberar-se delas. Nas décadas precedentes, surgiram reformas que ficaram muitas vezes no universo dos políticos e que eram até mesmo ignoradas por aqueles que deveriam colocá-las em prática. No contexto atual, no entanto, as obrigações aparecem mais numerosas, mais rígidas, mais profundas, mais codificadas e têm 
conseqüências concretas sobre as condições de trabalho e sobre o êxito dos alunos. Nesse sentido, pode-se pensar que as transformações do ensino no Canadá não são apenas uma nova moda que também passará. Compreende-se melhor, então, a importância para cada professor de garantir a sua "coerência profissional", o seu sentimento de direção (GOHIER, 2006). Todavia, nos perguntamos qual era o lugar ocupado pela comunidade profissional nesse contexto. Com efeito, como aponta Brassard (2003), concebemos que o indivíduo preocupado poderia procurar pistas de reposta junto à sua coletividade profissional, mas os dados examinados mostram que os professores utilizam pouco essa via para acalmar a intensidade de suas inquietações.

\section{Referências Bibliográficas}

BEN JAAFAR, S.; ANDERSON, S. E. Accountability in education: trends in Canada from 1990-2003. In: ANNUAL CONFERENCE OF THE CANADIAN SOCIETY FOR THE STUDY IN EDUCATION, 32, 2004, Manitoba. Accountability, professionalization and governance in Canadian education... Manitoba: University of Manitoba, 2004.

BRASSARD, A. Gestion du changement et intervention. Université de Montréal, 2003. (mimeo.).

CALDWELL, B. J. Education for the public good: strategic intentions for the $21^{\text {st }}$ century. In: ASCD. Preparing our schools for the $21^{\text {st }}$ century. Virginia: ASCD Yearbookm, 1999. p. 45-63.

CLOUTIER, M. Les préoccupations des directions d'école primaire à l'égard de leur rôle de facilitateur. In: CONGRÈS DE L'ASSOCIATION CANADIENNE FRANÇAISE POUR LE SAVOIR (ACFAS), 2006, Montréal. Anais... Montréal: ACFAS, 2006.

GERVAIS, G.; THORNY, I. L'offre et la demande des enseignants au niveau primaire et secondaire au Canada. Ottawa: Centre de la Statistique de l'éducation, 2001.

GOHIER, C. La construction de l'identité professionnelle de l'enseignant et du futur enseignant: éléments d'un programme de recherche. In: SÉMINAIRE D'ÉTÉ DU CENTRE DE RECHERCHE INTERUNIVERSITAIRE SUR LA FORMATION ET LA PROFESSION ENSEIGNANTE, 2006, Jouvence. Anais... Jouvence: Centre de Recherche Interuniversitaire, 2006. 
GRIMMETT, P.; DAGENAIS, D.; JACQUET, M.; ILIEVA, R. The contrasting discourses in the professional lives of educators in Vancouver, British Columbia. In: ANNUAL MEETING OF THE AMERICAN EDUCATIONAL RESEARCH ASSOCIATION, 2005, Montréal. The impact of educational policy on the social context of teachers' work in Canada... Montréal: American Educational Research Association, 2005.

GRIMMET, P.; WALDERN, B. Overview of trends and issues related to inclusion policy. 2006. (mimeo.).

HARGREAVES, A. The four ages of professionalism and professional learning. Unicorn, v. 23, n. 2, p. 86-114, 1997.

Teaching in the knowledge society: education in the ages of insecurity. New York: Teachers College, 2003.

LESSARD, C. Régulation multiple et encadrement du travail enseignant; éléments de comparaison canadienne. In: COLLOQUE INTERNATIONAL DE L'ASSOCIATION FRANCOPHONE D'ÉDUCATION COMPARÉE, 2006, Lille. Anais... Lille: Association Francophone, 2006.

MILES, M. B.; HUBERMAN, M. A. Analyse de données qualitatives. Bruxelles: De Boeck, 2003.

OCDE. L'école à la page. Formation etperfectionnement professionnel dês enseignants. Éditions OCDE, 1998.

PAILLÉ, P. De l'analyse qualitative en général et de l'analyse thématique en particulier. Revue de l'association pour la recherche qualitative, v. 15, p. 179-194, 1994.

PERRENOUD, P. Obligation de compétence et analyse du travail: rendre compte dans le métier d'enseignant. In: LESSARD, C.; MEIRIEU, P. (Éd.). L'obligation de résultats en éducation. Ste-Foy: Les Presses de l'Université Laval, 2004. p. 207-232.

RIOPEL, M. C.; TARDIF, M. Changements socio-éducatifs et point de vue d'enseignants du Québec: résultats préliminaires d'une étude longitudinale. In: CONGRÉS DE LA SOCIÉTÉ CANADIENNE POUR L'ÉTUDE DE L'ÉDUCATION, 31, 2003, Halifax. Promouvoir le dialogue... l'éducation comme réponse génératrice aux besoins de la collectivité. Halifax: Dalhousie 22 University, 2003.

Decentralization and reforms in education: impacts on teachers and school principals in the Montreal region. In: ANNUAL MEETING OF THE AMERICAN EDUCATIONAL RESEARCH ASSOCIATION, 2005, Montréal. The impact of educational policy on the social context of teachers' work in Canada... Montréal: American Educational Research Association, 2005. 
RIOPEL, M. C. Les directions d'établissement face au défi de la collaboration: résultats préliminaires d'une étude longitudinale. In: COLLOQUE DE L'ASSOCIATION MONTRÉALAISE DES DRECTION D'ÉTABLISSEMENT (AMDES), 2005, Magog. Anais... Magog: AMDES, 2005. SAVOIE, A.; BAREIL, C. Comprendre et mieux gérer les individus en situation de changement organisationnel. Revue Gestion, v. 24, n. 3, p. 82-94, 1999.

SAVOIE-ZAJC, L. L'accompagnement aux ajustements des pratiques professionnelles des personnels scolaires par la recherche-action. À paraître dans F. Cros, L'agir innovationnel. Bruxelles: De Boeck, 2006.

STATISTIQUES CANADA. Profil des langues an Canada: l'anglais, le français et bien d'autres langues. Recensement de 2001. Statistiques Canada, 2002.

TARDIF, M.; LESSARD, C. Le travail enseignant au quotidien. Ste-Foy: Lês Presses de l’Université Laval, 1999.

TARDIF, M. L'évolution du personnel de l'enseignement primaire et secondaire au Canadá. Description du projet de recherche. 2001. (mimeo.).

VAN DER MAREN, J. M. Méthodes de recherche pour l'éducation. 2e ed. Montréal: Presses de l'Université de Montréal, 1996.

(Tradução: Beatrice Reichen Vasconcelos Costa)

Recebido em: 30/09/2006

Aprovado em: 06/11/2006 